\title{
The Study on the Efficient HVDC Capacity Considering Extremely Low Probability of 765kV Double Circuit Transmission Lines Trip
}

\author{
Bong-Soo Moon ${ }^{\dagger}$, Boyung Ko* and Jin-San Choi**
}

\begin{abstract}
The load on the power grid of South Korea is expected to grow continuously until the late 2020s, and it is necessary to increase the transfer capacity from the Eastern grid to the Seoul-Gyeonggi region by reinforcing the transmission network for the electric power system to remain stable. To this end, the grid reinforcement by two bipole LCC HVDC transmission systems have been considered on account of the public acceptability and high growth of the fault current level, even though an additional $765 \mathrm{kV}$ system construction is more economical. Since the probability of the existing $765 \mathrm{kV}$ double circuit transmission line trip is extremely low, a dynamic simulation study was carried out to estimate the efficient HVDC capacity able to stabilize the transient stability by utilizing the HVDC overload capability. This paper suggests the application plan to reduce the HVDC construction capacity with ensuring the transient stability during the $765 \mathrm{kV}$ line trip.
\end{abstract}

Keywords: Double bipole HVDC transmission systems, $765 \mathrm{kV}$ double circuit transmission lines trip, HVDC continuous and overload capability

\section{Introduction}

The load on the power grid of South Korea is expected to experience continuous growth until the late 2020 s, and the ambitious expansion plans have been made to satisfy this growth in the load. However the growth for the load and generation are geographically displaced, whereas the load center is located in the Seoul-Gyeonggi area, a substantial part of the new generation capacity consisting of nuclear and coal power plants is planned along the northeast coast.

The load in the Seoul-Gyeonggi area is currently above $40 \%$ of the total load of South Korea and this trend will continue to the late 2020s, according to the long-term load forecast. The capacity of power plants in northeast coast is of about $8 \mathrm{GW}$ at the present, and it will reach about $22 \mathrm{GW}$ by the early 2020s. However, the load in the northeast area is only of about $2 \mathrm{GW}$. The transmission network in the northeast coast area consists of one $765 \mathrm{kV}$ transmission route and two $345 \mathrm{kV}$ transmission routes, and one transmission route consists of two transmission lines. The total thermal capacity of these transmission lines in the northeast coast area is only about $22 \mathrm{GW}$. Thus, the transmission network should be reinforced to increase the transfer capacity from the Eastern grid to the SeoulGyeonggi region so that the electric power system remains stable.

$\dagger$ Corresponding Author: Korea Electric Power Corporation \& Graduate School of Energy and Environment(Green school), Korea University, Korea. (bsmoon@kepco.co.kr)

* School of Electrical Engineering, Korea University, Korea (ok66551st@korea.ac.kr)

** Korea Electric Power Corporation, Korea. (jinsan.choi@kepco.co.kr) Received: August 18, 2016; Accepted: February 22, 2017
One alternative is to connect the Eastern grid with the Seoul Metro area using two bipole LCC HVDC converter systems consisting of transmission circuits rated from 3,500 to $4,500 \mathrm{MW}$ for each bipole. A $765 \mathrm{kV}$ transmission system can be more economical than an HVDC system because the distance of the transmission line will be $240 \mathrm{~km}$, but the construction of a $765 \mathrm{kV}$ transmission line will be disadvantageous in terms of public acceptability, and from a technical standpoint, the additional construction of $765 \mathrm{kV}$ transmission line results in a high growth in the fault current level, which is a big problem [1]. Due to the public acceptability and high growth of the fault current level, this paper considers the reinforcement of two bipole LCC HVDC transmission systems to increase the transfer capacity from Eastern grid to the Seoul-Gyeonggi area. The voltage of the two bipole HVDC transmission systems is $+/-500 \mathrm{kV}$, and their rectifiers are connected to the $345 \mathrm{kV}$ sides of the Hanul nuclear sites while inverters are connected to the $345 \mathrm{kV}$ side of the $765 \mathrm{kV}$ station and the $345 \mathrm{kV}$ station in the Seoul-Gyeonggi area.

The stability of the power system is evaluated in a dynamic study using the PSS/E, and the simulated contingencies are a double circuit contingency for the existing $765 \mathrm{kV}$ transmission lines and the reinforced two bipole HVDC transmission systems. Several contingencies were simulated involving outages in the sections of the $765 \mathrm{kV}$ double circuit between the northeast coast and the Metropolitan area. Transient stability for the KEPCO system is verified by checking whether the angle between generators converges or not after the major disturbance mentioned before $[2,3]$.

The loss of the $765 \mathrm{kV}$ double circuit transmission lines is severe condition, and a double circuit contingency in 
the side near the Metropolitan area of the of the $765 \mathrm{kV}$ transmission lines is especially severe because bypass transmission line for the tripped $765 \mathrm{kV}$ line is not enough.

The purpose of the two bipole LCC HVDC transmission systems is to provide a stable system that is capable of withstanding the loss of the $765 \mathrm{kV}$ double circuit transmission lines, which is the most severe condition. However, the probability of a $765 \mathrm{kV}$ double circuit transmission lines trip is extremely low. Therefore, implementing the overload capability on HVDC with reduced rated capacity is more reasonable than increasing the capacity of HVDC for continuous operation [4]. By utilizing the overloading characteristic of HVDC system, this paper verifies that rated capacity of HVDC can be reduced efficiently.

This paper consists of a dynamic study that was carried out to assess the continuous capability HVDC systems and HVDC systems with overload capability to determine the continuous and overload capability of HVDC systems in providing system stability against the loss of $765 \mathrm{kV}$ double circuit transmission lines. As a result, an efficient capacity for two bipole HVDC systems is proposed.

This paper is organized as follows. The next section describes the $765 \mathrm{kV}$ and double bipole HVDC system configuration in KEPCO power system. Section 3 presents the applied HVDC system parameter to simulate the overloading capability in PSS/e simulation. The comparative analysis results between the constant power order and the transient overloading operation of HVDC system is describe in Section 4. Finally, in Section 5, conclusion are drawn.

\section{System Description}

In South Korea, the power system is isolated without interconnection and in 2015, the peak load was $78,790 \mathrm{MW}$, the thermal, nuclear power generation is $97,650 \mathrm{MW}$ with the remainder being hydro, and the minimum load was $44,390 \mathrm{MW}$. The northern $765 \mathrm{kV}$ systems are connected to large thermal power plants on the west coast to the western Seoul-Gyeonggi area and also from large nuclear plants on the northeast coast to the eastern Seoul-Gyeonggi area. Now, two $765 \mathrm{kV}$ systems on the west coast and the northeast coast are once again interconnected as shown in Fig. 1.

The power system in the Seoul-Gyeonggi area is double looped with a $345 \mathrm{kV}$ system and connected to the large power plants on the west coast and east coast by five $345 \mathrm{kV}$ transmission routes consisting of ten transmission lines. The other southeast $765 \mathrm{kV}$ system is connected from large nuclear plants in the southeast coast to the Daegu area.

According to the additional construction plan of nuclear power plant on east coast, reinforcing the transmission line between eastern grid and Seoul-Gyeonggi region is necessary. Due to the public opposition on the addition

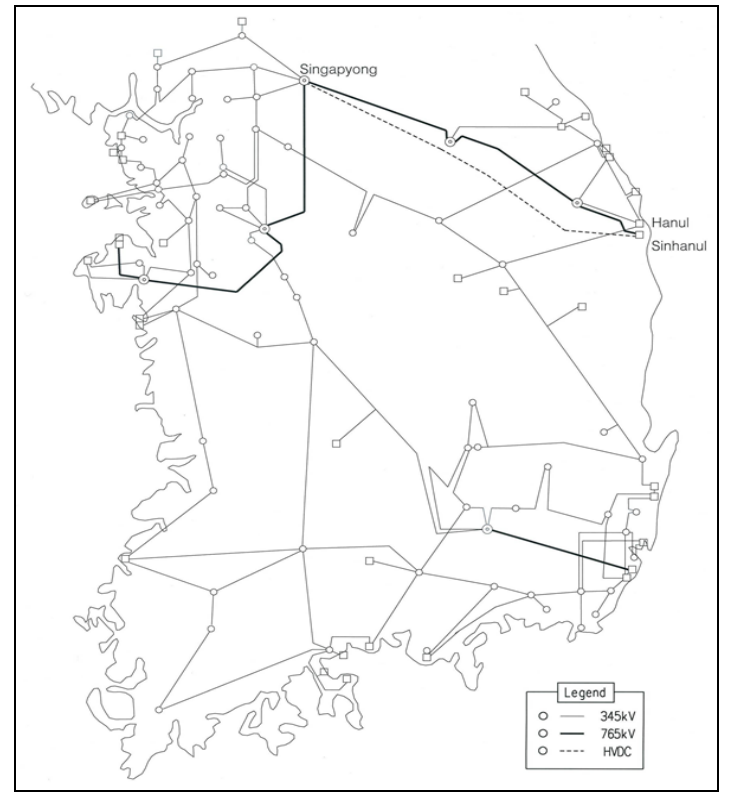

Fig. 1. The Korea power system diagram above $345 \mathrm{kV}$

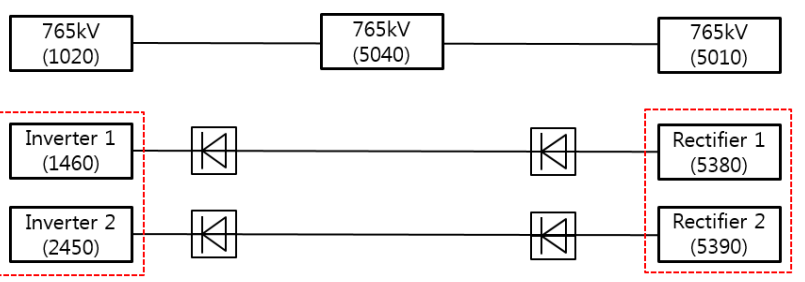

Fig. 2. $765 \mathrm{kV}$ AC line and double bipole HVDC system connecting the east coast generation site and Seoul load site

transmission line, double bipole LCC HVDC transmission system plan become influential. Therefore, in this paper, the double bipole HVDC system parallel with $765 \mathrm{kV}$ line, as shown in Fig. 2, will be considered in terms of a transient stability analysis through the PSS/e simulation [5].

\section{HVDC System Modeling Parameter}

This paper utilize the PSS/e power system simulator to conduct the transient stability during $765 \mathrm{kV}$ AC transmission line trip. The PSS/e generic CDC4t model is used to conduct the planning studies and detailed parameter is suggested below.

\subsection{Main circuit parameters}

\subsubsection{HVDC overhead lines and HVDC underground cables}

The total length is assumed to be $240 \mathrm{~km}$ with $50 \mathrm{~km}$ consisting of cable and the rest of overhead lines. The configuration includes 3 conductors (ACSR 2156MCM, 
Table 1. The electric parameters for the HVDC

\begin{tabular}{c|c|cc}
\hline \multicolumn{2}{c|}{ Type } & \multicolumn{2}{c}{ Parameter } \\
\hline $\begin{array}{c}\text { OHL } \\
\text { Data }\end{array}$ & $R_{\text {ОНL }}$ & $0.027 * \frac{190}{3}=1.71$ & {$[\Omega, \mathrm{ohm}]$} \\
& $L_{\text {ОНL }}$ & $0.568 * \frac{190}{3}=35.973$ & {$[\mathrm{mH}]$} \\
\hline \multirow{2}{\text{Cable}}{$\begin{array}{c}\text { Data } \\
\end{array}$} & $R_{\text {Cable }}$ & $0.0072 * \frac{50}{3}=0.12$ & {$[\Omega, \mathrm{ohm}]$} \\
& $L_{\text {Cable }}$ & $0.100 * \frac{50}{3}=1.667$ & {$[\mathrm{mH}]$} \\
& $C_{\text {Cable }}$ & $0.500 * 50 * 3=75.0$ & {$[\mu \mathrm{F}]$} \\
\hline
\end{tabular}

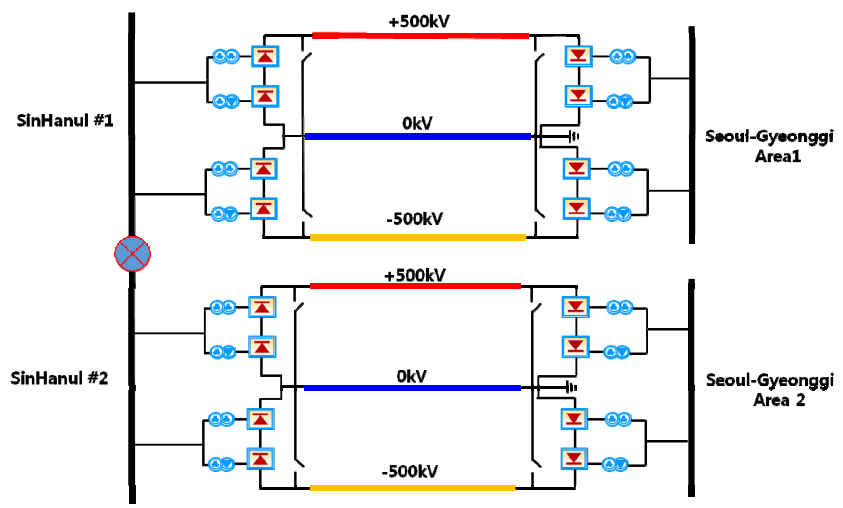

Fig. 3. Configuration of two bipole HVDC system with 12pulse thyristor bridge

Bluebird) per pole for the overhead line section and 3 conductors per pole $(2400 \mathrm{~mm} 2 \mathrm{Cu})$ for the underground section. The capacities for the overhead line and the cable section are 4,869A and 4,500A, respectively. The electric parameter for the HVDC OHL and the cable are shown in Table 1.

\subsubsection{Converter transformers}

For each pole converter, this paper assumes a 12-pulse bridge configuration consisting of two 6-pulse bridges connected in series with a $30^{\circ}$ phase shift that are supplied in turn by two groups of converter transformers, as shown in Fig. 3.

The impedances of the converter transformer are set as typical values shown in Table 2 .

Table 2. Percent impedance of the converter transformer

\begin{tabular}{c|c}
\hline $\mathrm{dxN}$ & $8 \%$ \\
\hline $\mathrm{drN}$ & $0.3 \%$ \\
\hline
\end{tabular}

\subsection{Dynamic models (CDC4t)}

The most dominating control parameters for the HVDC converter are related to the VDCOL (Voltage Dependent Current Order Limit) and the HVDC recovery characteristic.
Table 3. Applied parameter values for the VDCOL

\begin{tabular}{c|c|c|c}
\hline \multicolumn{4}{l}{ VDCOL Parameter Data } \\
\hline V_Block & $0.6 \mathrm{pu}$ & $\mathrm{C} 0$ & $530 \mathrm{amps}$ \\
V_Unblock & $0.65 \mathrm{pu}$ & $\mathrm{V} 1$ & $300 \mathrm{kV}$ \\
T_Block & $0.1 \mathrm{sec}$ & $\mathrm{C} 1$ & $3500 \mathrm{amps}$ \\
RSVOLT & $200 \mathrm{kV}$ & $\mathrm{V} 2$ & $400 \mathrm{kV}$ \\
RSCUR & $500 \mathrm{amps}$ & $\mathrm{C} 2$ & $4000 \mathrm{amps}$ \\
V_Ramp & $7 \mathrm{pu} / \mathrm{sec}$ & $\mathrm{V} 3$ & $500 \mathrm{kV}$ \\
C_ramp & $7 \mathrm{pu} / \mathrm{sec}$ & $\mathrm{C} 3$ & $5000 \mathrm{amps}$ \\
\hline
\end{tabular}

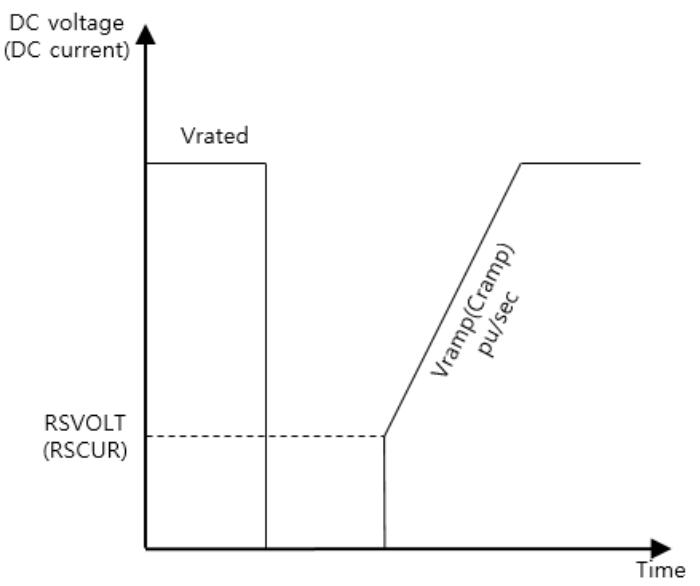

Fig. 4. Voltage and current recovery characteristic

VDCOL parameter should reflects the overloading capability of HVDC system. As shown in Fig. 4, the recovery characteristic is related to the ramp up ratio after the contingency occurrence. The values used for these control parameter are listed in Table 3. To verify the effect of the HVDC overloading, this paper apply the same parameter to both HVDC operation condition. One is with overloading and the other is without overloading condition.

\subsection{Overload characteristic of HVDC system}

Controllability of HVDC system can increase the transient stability of the AC system. With consideration on the thermal capacity of the rectifiers, HVDC system can be controlled in a manner such as ramped up and down quickly to balance the power between generation side and load side. This capability of HVDC system is very useful in helping the system from transient instability after a system fault. The HVDC overload capability can be applied as three type, i.e. continuous overload, shorttime overload and transient overload $[6,7]$. In this paper, considering the active power ramp-up ratio and the equipment capability, the transient overload is implemented. By reducing the rated HVDC capacity through the overloading operation, it will be verified that the efficient HVDC construction is possible with stable condition during the $765 \mathrm{kV}$ circuit contingency. After the disturbance occurs, the active power of each pole is overrated by 1.25 times of rated value. Through the simulation, the effect of 


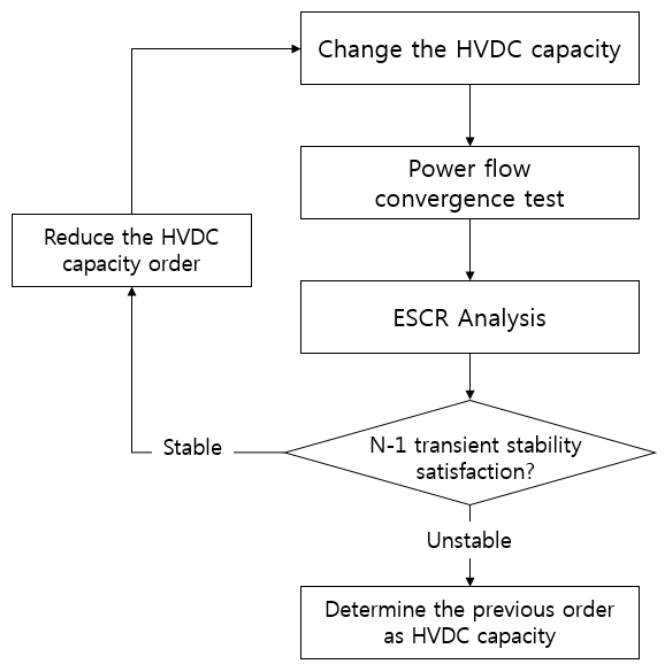

Fig. 5. Efficient HVDC capacity estimation flowchart

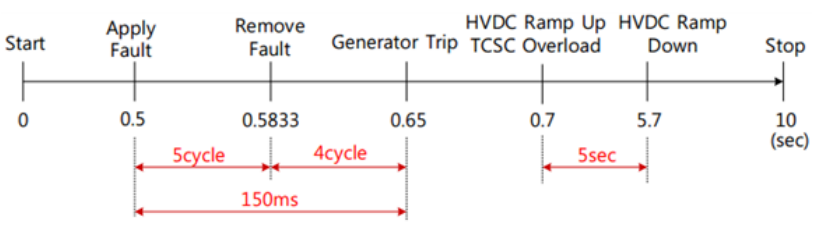

Fig. 6. Dynamic simulation process for KEPCO system

overloading on the power system transient stability is verified.

\section{Dynamic Simulation}

In this paper, PSS/e dynamic simulation is conducted to confirm the effects of power system stability after the $765 \mathrm{kV}$ AC circuit fault with double bipole LCC HVDC operation. Fig. 5 indicates the flowchart to estimate the efficient HVDC capacity maintaining the transient stability. Power flow convergence and ESCR analysis are conducted in terms of a steady-state analysis, and angle stability evaluation is performed as transient stability.

The power system stability was evaluated by carrying out a dynamic simulation on the angle spread of the power system, and the power flow on the HVDC system. Fig. 6 shows the dynamic simulation process given from the KEPCO's transient stability test rule. This process considers the time delay for fault detecting and generation tripping. The transient stability will be investigated whether the angle system of the system can be converge or not.

In this paper, two major $765 \mathrm{kV}$ line trip contingency is analyzed in term of transient stability. Fig. 7 shows the location of the line trip on $765 \mathrm{kV}$ AC circuit. This is the most severe possible contingency on the $765 \mathrm{kV}$ transmission line between the northeast coast to the SeoulGyeonggi area.
- Contingency 1: 1020-5040 765kV circuit trip

- Contingency 2: 5040-5010 765kV circuit trip

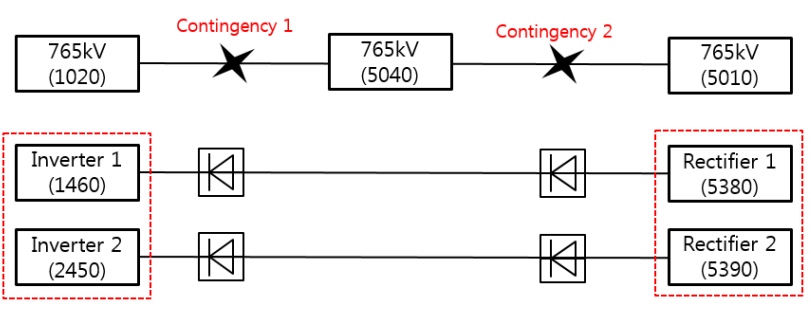

Fig. 7. Considered two main $765 \mathrm{kV}$ AC line contingency

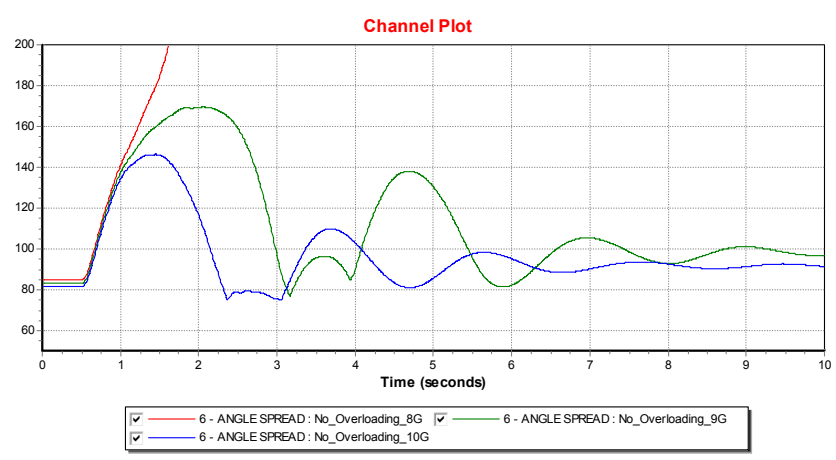

Fig. 8. Angle spread of power system without overloading (HVDC capacity: red-8GW, green-9GW, blue-10GW)

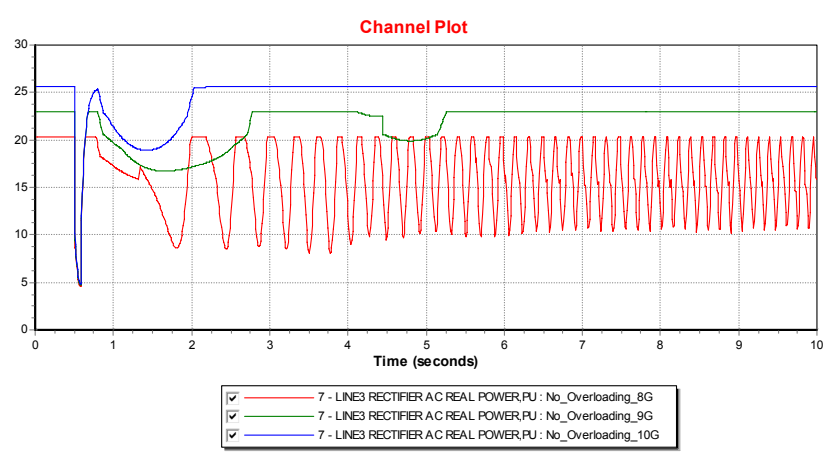

Fig. 9. DC power flow without overloading (HVDC capacity: red-8GW, green-9GW, blue-10GW)

\subsection{Contingency 1: Circuit trip between Bus1020- 5040}

This section shows the results of the dynamic simulation on the contingency analysis. The purpose of this simulation is to estimate the efficient HVDC capacity by applying the overloading capability. Therefore, the normal operation and the overloading operation of HVDC system are compared in terms of the transient stability.

Fig. 8 and 9 shows the transient characteristic of power system. With the increasing HVDC capacity, the system angle spread and DC power flow performances are improved as shown in Fig. 8. The DC power flow become more stable with increased capacity. The angle spread of 
AC system is reduced as well. The transient stability can be judged by angle spread of AC system, and the lower maximum value of spread angle means that the system is more stable. The power system with larger capacity of HVDC system shows robust characteristic in the $765 \mathrm{kV}$ line disturbance. However, larger capacity of HVDC system requires construction cost more, the capacity should be calculated with consideration on the cost and transient system stability. Through the PSS/e simulation, when the overloading operation is not applied, the HVDC capacity to stabilize the transient stability during $765 \mathrm{kV}$ line trip is required up to $9 \mathrm{GW}$.

This paper considers the effect of the overloading capability of HVDC system on transient stability. Overloading characteristic is applied in the manner described in Sec. 3, and the result is shown in Fig. 10, 11. When the overloading capability is applied, 7.5GW HVDC system is enough to stabilize the transient stability during the $765 \mathrm{kV}$ contingency. Therefore, through the simulation, it is verified that overloading capability is effective on the system stabilization.

\subsection{Contingency 2: Circuit trip between Bus5040- 5010}

For the purpose of estimation on the HVDC capacity, the possible contingencies on $765 \mathrm{kV}$ should be considered.

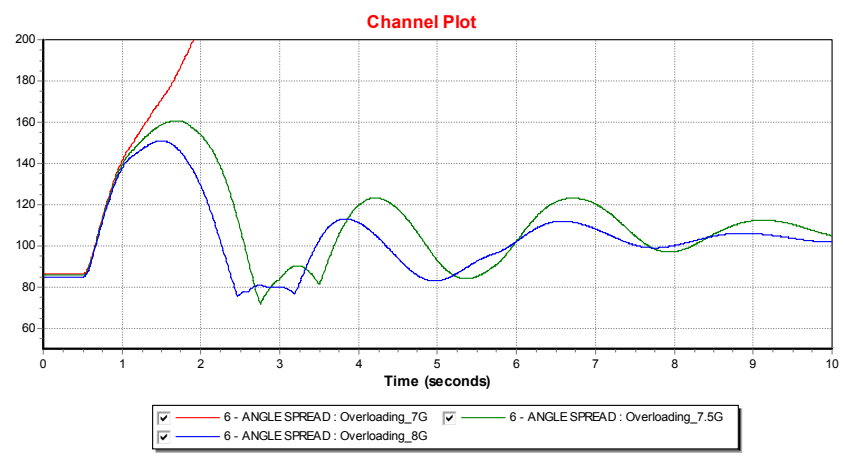

Fig. 10. Angle spread of power system with overloading (HVDC capacity: red-7GW, green-7.5GW, blue-8GW)

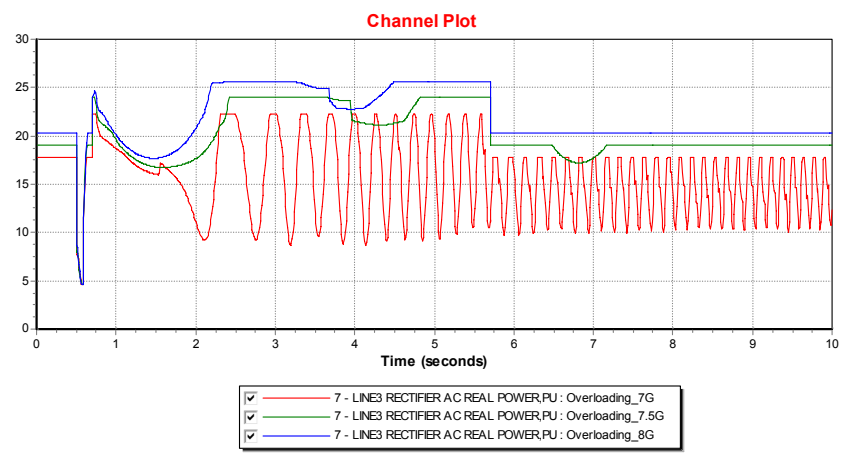

Fig. 11. DC power flow with overloading (HVDC capacity: red-7GW, green-7.5GW, blue-8GW)
Circuit trip between Bus 5040 and 5010 is also severe contingency and therefore it should be considered. The capacity estimation is conducted by similar process with contingency 1. As shown in Fig. 12 and 13 below, the double bipole HVDC system capacity without the overloading operation should reach $9 \mathrm{GW}$ to be in stable.

Fig. 14 and 15 represent the system result with overloading operation. By utilizing the overloading operation of HVDC system, 7.5GW of HVDC system is sufficient to make the power system stable during $765 \mathrm{kV}$ line trip contingency.

Through the abovementioned process, the HVDC capacity requirement for stabilizing the KEPCO power

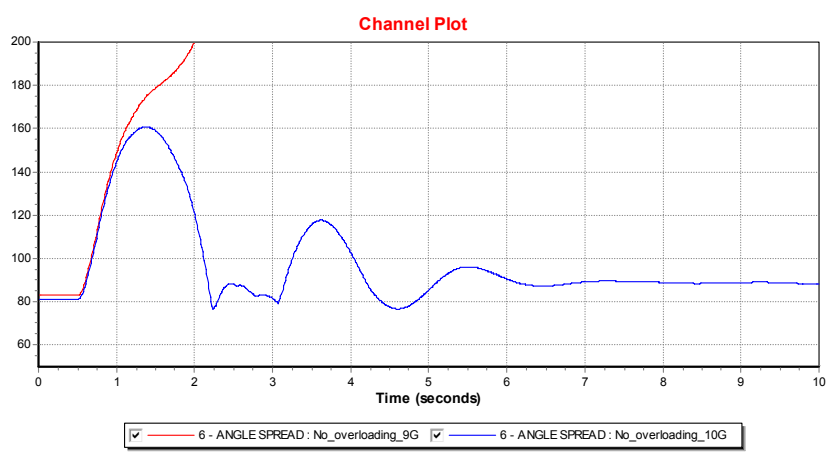

Fig. 12. Angle spread of power system without overloading (HVDC capacity: red-9GW, blue-10GW)

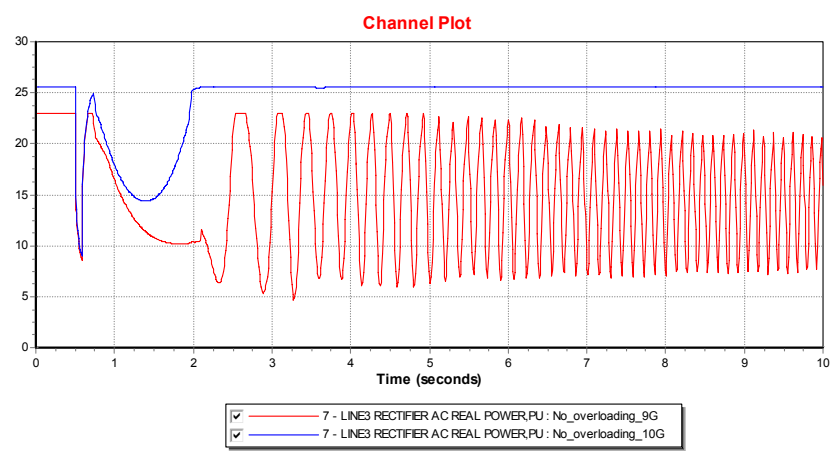

Fig. 13. DC power flow without overloading (HVDC capacity: red-9GW, blue-10GW)

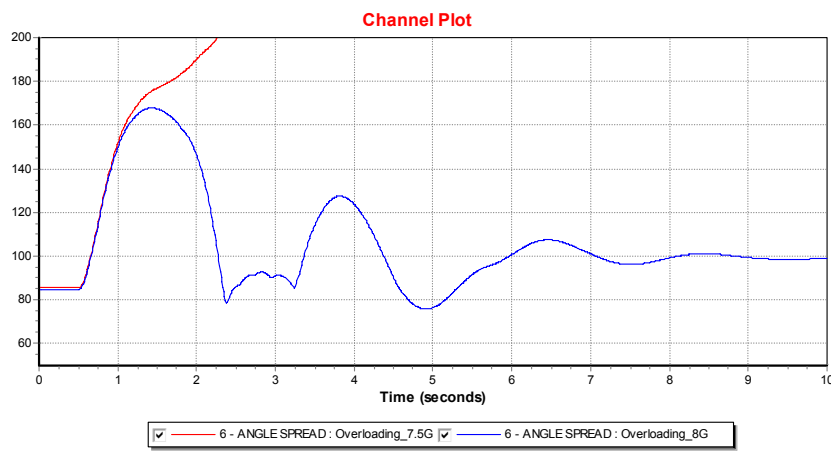

Fig. 14. Angle spread of power system with overloading (HVDC capacity: red-7.5GW, blue-8GW) 


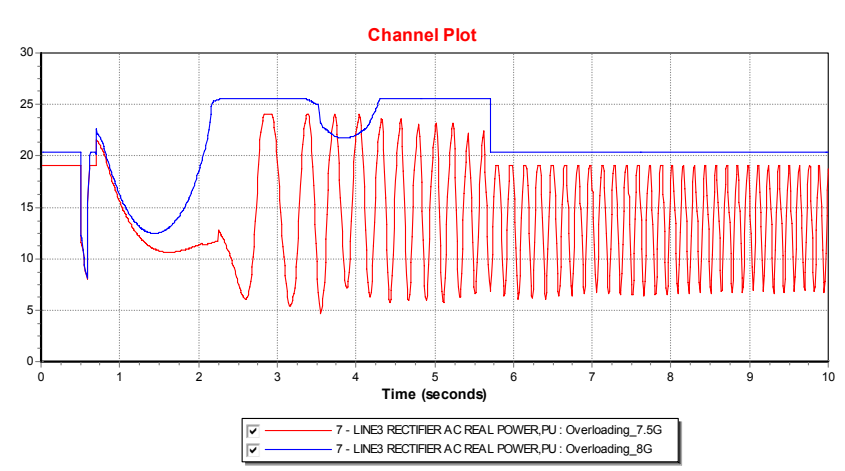

Fig. 15. DC power flow with overloading (HVDC capacity: red-7.5GW, blue-8GW)

Table 4. HVDC capacity requirement for transient stability

\begin{tabular}{c|cc}
\hline Required HVDC Capacity & & \\
\hline & Without Overloading & With Overloading \\
\cline { 2 - 3 } Contingency 1 & $9 \mathrm{GW}$ & $7.5 \mathrm{GW}$ \\
Contingency 2 & $10 \mathrm{GW}$ & $8 \mathrm{GW}$ \\
\hline
\end{tabular}

system can be estimated as Table 4. Considering the possible sever contingencies, 10GW of HVDC capacity is required without overloading operation. However, by utilizing the overloading capability of HVDC system, the required HVDC capacity can be reduced up to $8 \mathrm{GW}$. The HVDC capacity is directly related to the construction cost. Therefore, calculation on the efficient HVDC system capacity should be considered on a planning stage.

\section{Conclusion}

The transmission network reinforcement to increase the transfer capacity from the Eastern grid to the SeoulGyeonggi region is required to ensure stability in the electric power system. One alternative is to connect the Eastern grid with the Seoul Metro area using a $765 \mathrm{kV}$ transmission system that is more economical than an HVDC system, but on account of the public acceptability and the high growth of the fault current level this paper considers the reinforcement of two bipole HVDC transmission systems instead.

The probability of $765 \mathrm{kV}$ double circuit transmission lines trip is extremely low, and for this reason, installing a large capacity of HVDC system for transient stability can be inefficient. Therefore, this paper proposes a solution based on the overload capability of HVDC system to provide a stable condition against the loss of $765 \mathrm{kV}$ double circuit transmission lines. Through the PSS/e simulation, the $8 \mathrm{GW}$ double bipole HVDC with overloading capability can be constructed as a possible alternative to $10 \mathrm{GW}$ double bipole HVDC without overloading operation. This paper thus suggests the much more efficient HVDC system construction plan by considering that the probability for $765 \mathrm{kV}$ double circuit transmission lines trip is extremely low. For further research, overloading capability application on MTDC (Multi-terminal HVDC) topology can be worth considering, as $765 \mathrm{kV}$ line can be connected to HVDC system through an additional terminal.

\section{Acknowledgements}

This paper was supported by "Human Resources program in Energy Technology" of the Korea Institute of Energy Technology Evaluation and Planning (KETEP) granted financial resource from the Ministry of Trade, Industry \& Energy, Republic of Korea (No. 20154030200610)

\section{References}

[1] Md. Mizanur Rahman, Md. Fazle Rabbi, Md. Khurshedul Islam and F. M. Mahafugur Rahman, "HVDC over HVAC Power Transmission System: Fault Current Analysis and Effect Comparison," International Conference on Electrical Engineering and Information \& Communication Technology (ICEEICT) 2014, Dhaka, Bangladesh, Apr. 2014.

[2] Chan-Ki Kim, Gilsoo Jang, Jeong-Boo Kim and UgBo Shim, "Transient performance of Cheju-Haenam HVDC system," Power Engineering Society Summer Meeting 2001, Vancouver, Canada, Jul. 2001.

[3] Qing Zhong, Yao Zhang, Lingxue Lin, Qian Chen and Zhigang $\mathrm{Wu}$, "Study of HVDC Light for its enhancement of $\mathrm{AC} / \mathrm{DC}$ interconnected transmission systems," IEEE Power and Energy Society General Meeting - Conversion and Delivery of Electrical Energy in the 21st Century, Pittsburgh, USA, Jul. 2008.

[4] R. L. Lee, M. J. Beshir and J. H. Gee, "Planning Considerations for the Intermountain HVDC Transmission System," IEEE Transactions on Power Delivery, vol. 1, no. 1, pp. 225-231, Jan. 1986.

[5] Chan-Ki Kim, Gilsoo Jang, "A Study on an Operation Strategy of Dual-Infeed HVDC System," Journal of Electrical Engineering \& Technology, vol. 12, no. 1, pp.45-52, Dec. 2017

[6] M. Benasla, T. Allaoui, M. Brahami and A. Boudali, "Benefits of HVDC for Reducing the Risk of Cascading Outages and Large Blackouts in AC/DC Hybrid Grid," 3rd International Conference on Control, Engineering \& Information Technology (CEIT) 2015, Tlemcen, Algeria, May 2015.

[7] Xu Aidong, Wu Xiaochen, Hong Chao, Jin Xiaoming and Li Peng, "Study on Overload Capability and Its Application of HVDC Transmission System in China Southern Power Grid," IEEE PES PowerAfrica 2007 Conference and Exposition, Johannesburg, South Africa, Jul. 2007. 


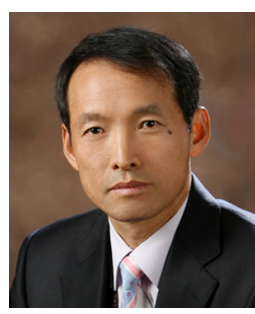

Bong-Soo Moon He received B.S degree in electrical engineering from Chung-Nam National University. He received M.S degree in electrical engineering from Seoul National University. His research interests are power system analysis and planning.

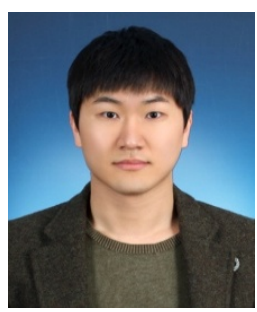

Bokyung Ko He received the B.S. and M.S. degrees in the school of electrical engineering from the Korea University in 2011 and 2013 respectively. He is currently pursuing his Ph.D. degree in electrical engineering from Korea University. His research interests include AC/DC system analysis and control.

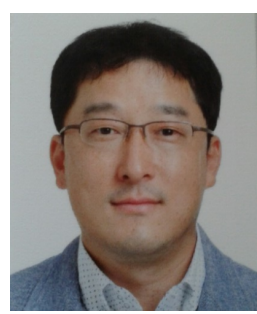

Jin-San Choi He received B.S. and M.S. degrees in electrical engineering from Seoul National University. His research interests are power system analysis and HVDC planning. 